\title{
A Quality Improvement Survey to Assess Pain Management in Cardiac Surgery Patients
}

\author{
Mohammad Hamid, Amar Lal Gangwani, Mohammad Irfan Akhtar \\ Aga Khan University, Karachi, Pakistan \\ Email: mohammad.irfan@aku.edu, amar.gangwani@aku.edu, mohammad.hamid@aku.eduAbstract
}

Received 11 December 2014; accepted 23 May 2015; published 29 May 2015

Copyright (C) 2015 by authors and Scientific Research Publishing Inc.

This work is licensed under the Creative Commons Attribution International License (CC BY). http://creativecommons.org/licenses/by/4.0/

(c) $\underset{\mathrm{EY}}{\mathrm{E}}$ Open Access

\section{Abstract}

Objective: To evaluate the quality of pain management in cardiac ICU patients by using a questionnaire. Methodology: All post cardiac surgery patients between 18 and 75 years old were included in this survey. Chronic pain patients, paediatric patients, emergency surgeries were excluded. A predesigned proforma was prepared according to American Pain Society recommendations and distributed among Cardiac ICU patients after 24 hours of extubation. This proforma was explained to the patients and collected later. The questionnaire was related to pain severity, aggravating and relieving factors, side effects of analgesics, affective experience and satisfaction with pain management. Results: Total 308 patients participated in one year period. $243(78.9 \%)$ were male and $65(21.1 \%)$ were female. Multimodal analgesia was used in most of the patients. Severity of pain was described as mild $70 \%$ and moderate $28.6 \%$. Most of the patients complained of sharp pain $100(37.5 \%)$, mainly at the site of incision $129(41.9 \%)$. The main aggravating factor associated with increased pain was deep breathing $118(39.8 \%)$ while pain was minimized by taking pain medications $\mathbf{4 0 . 6 \%}$. A significant association was found between preoperative counseling about pain options and satisfaction. $96.8 \%$ reported satisfaction with pain management. Conclusion: Although overall pain control was reported as adequate and patients were highly satisfied, there were areas which need further improvement. These include strategies to provide preoperative information about postoperative pain management and better training of medical staff to assess and manage pain. Additionally, the concerns and fears of patients about pain treatment need to be addressed.

\section{Keywords}

Analgesia, Cardiac Surgical Procedures, Pain Management, Questionnaires 


\section{Introduction}

Effective pain management after cardiac surgery is essential to prevent poor outcome. There is a higher incidence of chronic (21\% - 55\%) [1] pain in cardiac surgery patients due to various reasons. Pain after cardiac surgery is different from other surgeries mainly because of various sites of origin of pain and several aggravating factors. Pain occurs not only at the incision site but also at the chest tube insertion site. In addition, pain also occurs at the site of invasive lines, veins harvesting site and at back due to prolonged intubation and immobility. Presence of Foley's catheter, ETT suctioning and change in position further aggravate this pain. Additionally, anxiety associated with major surgery and postoperative intubation also plays a major role in aggravating pain. Intensity of pain is also aggravated by nursing and medical interventions.

Pain originates from muscles, bone, ligaments and tendons due to incision and sternal retraction. Fractured ribs and dislocation of costochondral junction and joint between ribs and spine are not uncommon [2]. Pain is also more common in patients who have LIMA harvesting possibly due to intercostal nerves injury [3].

Various methods have been used to control post cardiac surgery pain and these include narcotic and nonnarcotic analgesic drugs in bolus doses or in infusion forms. Non pharmacological techniques have also been tried to relieve pain. These include distraction techniques, application of cold or hot packs, meditation, and massage. The undertreated acute and severe pain leads to tachycardia, atelectasis and pneumonia, increased oxygen consumption, hyperglycemia and chronic pain.

American Pain Society [4] has developed a patient outcome questionnaire to assist organizations in improving quality of pain management. This patient outcome questionnaire was initially published in 1991; later few alterations were made in 1995 and then again revised in 2010. These revised recommendations were modified according to the local environment. Being a third world country with low literacy rate, it was decided to further simplify this questionnaire.

The objective of the survey was to evaluate the quality of postoperative pain management in cardiac surgery patients by using modified American Pain Society’s patient outcome questionnaire.

\section{Methodology}

This prospective survey was conducted in the cardiac intensive care unit (CICU) of Aga Khan University Hospital Karachi. This study was approved by departmental research committee. All post cardiac surgery patients between the age of 18 and 75 were included in this one year survey. Patients excluded from this study were those who required reopening for bleeding, extubated after 24 hours of CICU stay, discharged from CICU within 24 hrs. of extubation, unable to understand the survey form, admitted with IABP, chronic pain patients, patients on antipsychotic drugs and all the emergency cases.

\section{Data Collection Procedure}

A questionnaire in English and Urdu was distributed among CICU patients after 24 hours of extubation and collected later. The patients were selected using non-probability sampling. If patients cannot fill out the survey form due to any reason, then a resident was allowed to fill it out via face to face interview. Survey form was explained to the patients and consent was taken preoperatively.

All data was recorded on a survey form, which included demographics and 15 questions related to pain severity, its effect on activity, side effects, affective experience and satisfaction. All information on the form was entered in SPSS by a research assistant.

Statistical analysis was performed using Statistical Packages for Social Science version 19 (SPSS Inc., Chicago, IL). Frequency and percentages were computed for categorical observation and analyze by chi-square test while mean and standard deviation were estimated for numeric variables and analyzed by the independent sample test or Mann-Whitney $\mathrm{U}$ test. $\mathrm{P} \leq 0.05$ was considered as significant.

\section{Results}

Total 308 patients participated in the survey. Out of these 243 (78.9\%) were males while 65 (21.1\%) were females. Mean age of all the patients was $56.15 \pm 10.85$. Most of the patients $248(80.5 \%)$ underwent coronary artery bypass surgery and only $22(7.14 \%)$ had valvular surgery while rest of the patients had combination of procedures. Modalities of pain management included intravenous infusion 41 (13.3\%) and PCIA 23 (7.5\%). There 
were 290 (94.2\%) patients who received 1 gm of intravenous paracetamol 6 hourly. Multimodal analgesia was used in most of the patients. Fixed and regular dose of narcotics was given in 269 (87.3\%) patients while break through pain was managed by intermittent boluses of either morphine or tramadol. Commonly used drugs were tramadol 227 (73.7\%), ketorolac 107 (34.7\%) and morphine 116 (37.7\%).

Left internal mammary artery (LIMA) was harvested in 215 (82.06) patients. These patients included CABG only and combination with other procedures.

A significant reduction of pain was associated with use of morphine and tramadol (P-value $<0.05$ ). Overall pain intensity was described as mild $216(70.1 \%)$ and moderate 88 (28.6\%) while aggravating factor for pain was mainly deep breathing 118 (39.8\%) and ambulation 86 (27.9\%). Pain intensity was minimized by taking pain medications $40.6 \%$ or by staying immobile 66 (21.4\%). Intensity of pain was relieved further after chest drain removal 80 (26\%).

The commonest pain type was described as cutting or sharp 100 (37.5\%) followed by pressure $77(25 \%)$ and burning 68 (22.1\%). Pain was presented at the site of incision (Median sternotomy) in 129 (41.9\%) patients followed by chest drain site 104 (33.8\%) (Table 1).

Table 1. Intensity of pain and patients experiences.

\begin{tabular}{|c|c|}
\hline Pain related investigation & n (\%) \\
\hline \multicolumn{2}{|l|}{ Factors associated with pain during CICU stay after extubation } \\
\hline Deep breathing & 118(39.8\%) \\
\hline Ambulation & $86(27.9 \%)$ \\
\hline Turning or change of position & $29(9.4 \%)$ \\
\hline Chest tube removal & $62(20.1 \%)$ \\
\hline Back pain & $1(0.3 \%)$ \\
\hline Deep breathing + Ambulation & $9(2.9 \%)$ \\
\hline Deep breathing + Turning or change of position & $3(1 \%)$ \\
\hline \multicolumn{2}{|l|}{ Pain intensity since extubation } \\
\hline Mild & $216(70.1 \%)$ \\
\hline Moderate & $88(28.6 \%)$ \\
\hline Severe & $4(1.3 \%)$ \\
\hline \multicolumn{2}{|l|}{ What percentage of time, you were in severe pain during ICU stay } \\
\hline$\leq 30 \%$ & $239(77.6 \%)$ \\
\hline $30 \%$ to $50 \%$ & $59(19.2 \%)$ \\
\hline$>50 \%$ & $10(3.2 \%)$ \\
\hline \multicolumn{2}{|l|}{ Did your pain relived or minimized by } \\
\hline Rest/staying immobile & $66(21.4 \%)$ \\
\hline Pain medications & $125(40.6 \%)$ \\
\hline Breathing superficially & $33(10.7 \%)$ \\
\hline Rubbing the pain site or holding a pillow on the chest & $4(1.3 \%)$ \\
\hline After chest tube removal & $80(26 \%)$ \\
\hline \multicolumn{2}{|l|}{ What type of pain did you experienced } \\
\hline Cutting/sharp & $100(32.5 \%)$ \\
\hline Burning & $68(22.1 \%)$ \\
\hline Throbbing & $63(20.5 \%)$ \\
\hline Pressure & $77(25 \%)$ \\
\hline \multicolumn{2}{|l|}{ Where did you feel the pain mostly } \\
\hline Site of incision & $129(41.9 \%)$ \\
\hline Chest tube site & 104(33.8\%) \\
\hline Back pain & $22(7.1 \%)$ \\
\hline Throat & $1(0.3 \%)$ \\
\hline Everywhere & $3(1 \%)$ \\
\hline Site of incision + Chest tube site & $22(7.1 \%)$ \\
\hline Site of incision + Back pain & $1(0.3 \%)$ \\
\hline Chest tube site + Back Pain & $14(4.5 \%)$ \\
\hline Site of incision + Chest tube site + Limbs & $1(0.3 \%)$ \\
\hline Back Pain + Throat & $1(0.3 \%)$ \\
\hline
\end{tabular}


Options for pain control were discussed in only 120 (39\%) patients during preoperative visit by the anaesthetists. These patients also had higher satisfaction levels $89.2 \%$ than those who did not receive information about pain control (P-value < 0.004). Nausea 90 (29.2\%) and drowsiness 91 (29.5\%) were the major side effects mentioned by the patients (Table 2).

The association of gender and type of surgery with overall pain control was also assessed by chi-square test but no statistical significance was found.

There were $96.8 \%$ patients found to be satisfied with the pain management, despite the fact that $44.8 \%$ would have liked to receive more pain medications and 30\% complained of moderate to severe pain. Significant association was found among satisfaction and intensity of pain, type of pain and percentage of time participants experienced the pain $(\mathrm{P}$-value $<0.05)$. Satisfaction grades were significantly increased when pain options were discussed preoperatively, patients received pain killers and when asked whether they would have liked to receive more pain killers (Table 3).

Intensity of pain was significantly reduced when patient asked for pain killers (P-value $=0.005)$ but preoperative information about pain management options had no influence on the intensity of pain $(\mathrm{P}-\mathrm{value}=0.32)$. Anxiety was also associated with pain in about $50 \%$ of patients while few patients suffered depression. Out of 216 patients who complained of mild or no pain, about 129 also felt that it was pain causing the anxiety. There seems to be no correlation between the anxiety and severity of pain.

There were 138 patients who would like to receive more pain medications but they never called the nurses to provide them with the pain killers. Out of 44 patients who asked for pain killers, about 35 said they wanted more pain medication.

\section{Discussion}

Pain after cardiac surgery is often undertreated [5] [6] and moderate to severe pain [7] is a common complaint in CICU. Pain management is observed to be inadequate and often neglected in the overall management which potentially leads to undesirable consequences [8]. Negative impact may be noticed on cardiac, pulmonary, gastrointestinal and renal functions, if postoperative pain is not managed adequately. In addition, persistent acute postoperative pain [9] may lead to the development of chronic pain [10] [11].

In the present survey, the overall pain control was good to excellent and most of the survey participants were satisfied with the pain management in CICU. Patient's opinion at the time of survey could be affected by several unmeasured factors like mood at the time of survey, understanding of questions and unrelated aspects of patient care. This source of error most likely would be distributed equally throughout the cohort. The intubation period was excluded from the survey because previous studies had also shown that some of the patients were not able to recall the intubation period [12].

Table 2. Responses regarding information of pain, medication services.

\begin{tabular}{|c|c|c|}
\hline Response regarding information and satisfaction of pain & & n (\%) \\
\hline Did you receive any information about pain treatment options before surgery & Yes Responses & $120(39 \%)$ \\
\hline Did you feel that the pain was interfering with your mobility or movement & Yes Responses & $196(63.6 \%)$ \\
\hline Did you wake up by pain during CICU stay & Yes Responses & $53(17.2 \%)$ \\
\hline Have you had any of these side effects & $\begin{array}{c}\text { Nausea } \\
\text { Vomiting } \\
\text { Itching } \\
\text { Dizziness } \\
\text { Drowsiness }\end{array}$ & $\begin{array}{c}90(29.2 \%) \\
32(10.4 \%) \\
13(4.2 \%) \\
73(23.7 \%) \\
91(29.5 \%)\end{array}$ \\
\hline Did the pain cause you to feel & $\begin{array}{c}\text { Anxious } \\
\text { Depressed } \\
\text { Frightened } \\
\text { helpless }\end{array}$ & $\begin{array}{c}166(53.9 \%) \\
36(11.7 \%) \\
30(9.7 \%) \\
20(6.5 \%)\end{array}$ \\
\hline How satisfied you are with your pain treatment during CICU stay & $\begin{array}{l}\text { Excellent } \\
\text { Good } \\
\text { Satisfactory } \\
\text { Poor }\end{array}$ & $\begin{array}{c}114(37 \%) \\
132(42.9 \%) \\
52(16.9 \%) \\
10(3.2 \%)\end{array}$ \\
\hline Would you have liked to have received more pain medication & Yes Responses & $138(44.8 \%)$ \\
\hline Have you asked for pain killers during this time & Yes Responses & $44(14.3 \%)$ \\
\hline
\end{tabular}


Table 3. Comparison of satisfaction of pain treatment and factor related to satisfaction.

\begin{tabular}{|c|c|c|c|c|c|c|}
\hline \multirow{2}{*}{ Variables } & \multicolumn{5}{|c|}{ Satisfaction with your pain treatment during CICU stay } & \multirow{2}{*}{$\begin{array}{c}\text { P-valu } \\
\text { e }\end{array}$} \\
\hline & Total & Excellent & Good & Satisfactory & Poor & \\
\hline Pain intensity & & & & & & 0.0005 \\
\hline Mild & 216 & $105(48.6 \%)$ & $97(44.9 \%)$ & $13(6 \%)$ & $1(0.5 \%)$ & \\
\hline Moderate to severe & 92 & $9(9.8 \%)$ & $35(38 \%)$ & $39(42.4 \%)$ & $9(9.8 \%)$ & \\
\hline \multicolumn{7}{|l|}{ Type of Pain } \\
\hline Cutting/sharp & 100 & $23(23 \%)$ & $36(36 \%)$ & 33(33\%) & $8(8 \%)$ & 0.0005 \\
\hline Burning & 68 & $23(33.6 \%)$ & $38(55.9 \%)$ & $7(10.3 \%)$ & $0(0 \%)$ & 0.032 \\
\hline Throbbing & 63 & $19(30.2 \%)$ & $33(52.4 \%)$ & $8(12.7 \%)$ & $3(4.8 \%)$ & 0.25 \\
\hline Pressure & 77 & 49(63.6\%) & $24(31.2 \%)$ & $4(5.2 \%)$ & $0(0 \%)$ & 0.0005 \\
\hline $\begin{array}{l}\text { What percentage of time, you were in severe pain } \\
\text { during ICU stay }\end{array}$ & & & & & & 0.0005 \\
\hline$\leq 30 \%$ & 239 & 104(43.5\%) & $107(44.8 \%)$ & $25(10.5 \%)$ & $3(1.3 \%)$ & \\
\hline $30 \%$ to $50 \%$ & 59 & $10(16.9 \%)$ & 23(39\%) & $23(39 \%)$ & $3(5.1 \%)$ & \\
\hline$>50 \%$ & 10 & $0(0 \%)$ & $2(20 \%)$ & $4(40 \%)$ & $4(40 \%)$ & \\
\hline $\begin{array}{l}\text { Did you receive any information about pain treatment } \\
\text { options before surgery }\end{array}$ & & & & & & 0.0005 \\
\hline Yes & 120 & $65(54.2 \%)$ & $42(35 \%)$ & $12(10 \%)$ & $1(0.8 \%)$ & \\
\hline No & 188 & $49(26.1 \%)$ & $90(47.9 \%)$ & $40(21.3 \%)$ & $9(4.8 \%)$ & \\
\hline $\begin{array}{l}\text { Would you have liked to have received more } \\
\text { pain medication }\end{array}$ & & & & & & 0.0005 \\
\hline Yes & 138 & $30(21.7 \%)$ & $62(44.9 \%)$ & $38(27.5 \%)$ & $8(5.8 \%)$ & \\
\hline No & 170 & $84(49.4 \%)$ & $70(41.2 \%)$ & $14(8.2 \%)$ & $2(1.2 \%)$ & \\
\hline Have you asked for pain killers during this time & & & & & & 0.0005 \\
\hline Yes & 44 & $8(18.2 \%)$ & $14(31.8 \%)$ & $16(36.4 \%)$ & $6(13.6 \%)$ & \\
\hline No & 264 & $106(40.2 \%)$ & $118(44.7 \%)$ & $36(13.6 \%)$ & $4(1.5 \%)$ & \\
\hline
\end{tabular}

Multimodal pain management is essential for effective pain management. It also reduces the side effects of individual drugs. Combination of paracetamol and tramadol was the most commonly used therapy in this study. Morphine was administered for breakthrough pain on as per need basis. Yorke et al. [13] used prn boluses of morphine in cardiac surgery patients and found that smaller amount of morphine was used. In their study most of the patients complained of moderate to severe pain and older patients received less morphine. This was observed in previous studies that medical staff usually administered less morphine to older patients [13].

Moderate type of pain was experienced by $33.6 \%$ of patients in whom left IMA was harvested while only $24 \%$ complaint of moderate pain when left IMA was not used for coronary artery bypass. This difference did not reach to a statistically significant level. It has been identified in previous studies as well [14] that IMA harvesting is associated with significant pain [15] [16]. Ischaemic injury to the intercostal nerves is the purported mechanism of injury.

The majority of the patients described their pain as cutting or sharp in contrast to the study of Aslan et al. [17] which reported aching and throbbing being the main description and only 10\% patients described their pain as sharp. Patients in a study by Janelle et al. described post cardiac surgery pain as tender which was a milder form of pain. It is needed to remember the expression of pain is very subjective and modified by several factors including, social, environmental, psychological and cultural factors [17].

Pain was increased by deep breathing, ambulation and chest tube removal. This observation is also endorsed by Mello et al. who described coughing and deep breathing as the aggravating factors for pain in most of the cardiac surgical patients [18]. Celine et al. identified a significant association with increased pain and deep breathing in intubated patients. A decrease in pain was subsequently observed when pain medications were administered and patients were allowed to rest. 
Pain intensity was moderate to severe in most of the older studies [19]. This statement may be less true today, given the changes in practice have occurred over the last decade. The changes include awareness regarding the detrimental effects of pain, emergence of proactive pain management, more emphasis on assessment and protocol based multimodal treatment [20]. There were only few who complained of severe pain after extubation in our participants but when asked about the percentage of time they were in pain during CICU stay (including intubation duration) then about $42 \%$ reported severe pain in 30\% - 40\% of time. Moreover, $95.8 \%$ patients in mild pain stated that they spent $<30 \%$ time in pain. Pain intensity usually decreases each day. Reduced intensity of pain was noticed in older patients as compared to less than 60 years old patients [8].

Patients felt pain mostly at the site of incision and at the chest tube insertion site. Janelle et al. also noticed in their survey that 92\% participants experience pain at the site of incision on chest [13]. Sternal incision on the chest was the most frequently reported site of pain in other studies [12], but other sites should also be considered during pain management. Chest drains obviously causes pain but back pain is not uncommon in cardiac surgical patients. Back pain may be related to prolonged surgery and patient's position in CICU.

Most of the participants did not receive any information about the intensity of pain after surgery and pain management options. Of those who complained of moderate or severe pain, $65 \%$ did not receive any information on pain management prior to surgery. Preoperative counseling concerning postoperative pain management had an impact on the satisfaction level [21]. Satisfaction level was graded as good to excellent by $89.2 \%$ of the patients who received preoperative counseling. Patient perceptions of postoperative pain have been shown to be significantly reduced by preoperative counseling [22]. The intensity of pain felt by the patients lessens if they are informed as compared to uninformed patients. Informing patients preoperatively about postoperative pain should be a regular feature of preoperative assessment and counseling. The patients should be informed to expect pain after surgery and be advised on the availability and appropriate use of pain killers to manage postoperative pain.

Drowsiness and nausea were the most common side effects noticed by the patients. Incidence of nausea in one of the study was $12 \%$ [5]. Although, the incidence of nausea was the same in both groups, higher incidence of vomiting was noticed in tramadol group (12.3\%) than morphine group (6\%). Higher incidence of nausea in study population was probably due to the fact that intravenous tramadol was the main narcotic given to the patients.

Studies have indicated that patients are reasonably satisfied with their pain management in CICU [22]. Raksamani et al. [23] also observed a high satisfaction level in post cardiac surgery patients despite high incidence of moderate to severe pain (61.4\%). In our study almost $97 \%$ of the participants showed high grades of satisfaction concerning the pain management during their CICU stay but unfortunately $30 \%$ patients were in moderate to severe pain and $44.8 \%$ would have liked to receive more pain medication. Overall management and individualized care in the intensive care units probably made the patients satisfied with the pain management. As expected, $93.5 \%$ of patients with mild pain termed their satisfaction grade as good to excellent while only $9.8 \%$ patients with moderate to severe pain described their satisfaction level as excellent (P-value $<0.05$ ). Cutting and sharp pain seemed to be less acceptable for the patients as compared to pressure sensation. This is reflected by better satisfaction grades in patients who express pain as pressure sensation (94.8\% vs 59\%).

Pain medications played a major role in relieving pain while patients were also more comfortable after the chest tube removal and by staying immobile and breathing superficially. Almost $45 \%$ would have wanted to receive more pain medications during their stay in CICU. Patients usually have many misconceptions and beliefs about pain medications [2]. They try to avoid pain medications due to the fear of addiction, side effects of medications and erroneous thinking of reserving medications only for severe pain. Few patients believed that it was normal to have pain after surgery and pain might help in recovery. Nurses usually underestimate patient's pain which ultimately leads to under treatment [19]. Training of patients and medical staff [24] is very much needed to remove these fears.

As shown in previous studies that patients usually wait for nurses/physician to assess their pain which makes it very important for staff to assess pain and treat them early [25]. Despite the fact in our study, $30 \%$ of the times these patients were in pain and $45 \%$ would have liked to receive more pain medication but surprisingly only $14 \%$ of patients asked for pain killers during this time. This is established by Janelle et al. as well, where fewer than $50 \%$ communicated their pain to nurses/physicians. Patients are reluctant to ask for pain killers due to the fear of addiction and drug induced side effects [5]. Pain management program with specific guidelines also have a role in managing postoperative pain effectively. Jocelyn et al. in their practice guideline used paracetamol and In- 
domethacin (NSAID) on regular basis along with intermittent doses of intravenous morphine and found that it was $95 \%$ effective in relieving pain [26].

\section{Conclusion}

Overall pain management was perceived as adequate and patients were highly satisfied in our survey. Areas which still need improvement include strategies to provide preoperative information about postoperative pain management and better training of medical staff to assess and manage pain. Additionally, the concerns and fears of patients about analgesics, especially narcotics, need to be addressed.

\section{References}

[1] Lahtinen, P., Kokki, H. and Hynynen, M. (2006) Pain after Cardiac Surgery: A Prospective Cohort Study of 1-Year Incidence and Intensity. Anesthesiology, 105, 794-800. http://dx.doi.org/10.1097/00000542-200610000-00026

[2] Cogan, J., Ouimette, M.F., Vargas-Schaffer, G., Yegin, Z., Deschamps, A. and Denault, A. (2014) Patient Attitudes and Beliefs Regarding Pain Medication after Cardiac Surgery: Barriers to Adequate Pain Management. Pain Management Nursing, 15, 574-579. http://dx.doi.org/10.1016/j.pmn.2013.01.003

[3] Markman, P.L., Rowland, M.A., Leong, J.Y., Van Der Merwe, J., Storey, E., Marasco, S., et al. (2010) Skeletonized Internal Thoracic Artery Harvesting Reduces Chest Wall Dysesthesia after Coronary Bypass Surgery. The Journal of Thoracic and Cardiovascular Surgery, 139, 674-679. http://dx.doi.org/10.1016/j.jtcvs.2009.03.066

[4] Gordon, D.B., Polomano, R.C., Pellino, T.A., Turk, D.C., McCracken, L.M., Sherwood, G., et al. (2010) Revised American Pain Society Patient Outcome Questionnaire (APS-POQ-R) for Quality Improvement of Pain Management in Hospitalized Adults: Preliminary Psychometric Evaluation. The Journal of Pain, 11, 1172-1186. http://dx.doi.org/10.1016/j.jpain.2010.02.012

[5] Reimer-Kent, J. (2003) From Theory to Practice: Preventing Pain after Cardiac Surgery. American Journal of Critical Care, 12, 136-143.

[6] Cogan, J. (2010) Pain Management after Cardiac Surgery. Seminars in Cardiothoracic and Vascular Anesthesia, 14, 201-204. http://dx.doi.org/10.1177/1089253210378401

[7] Bjornnes, A.K., Rustoen, T., Lie, I., Watt-Watson, J. and Leegaard, M. (2014) Pain Characteristics and Analgesic Intake before and Following Cardiac Surgery. European Journal of Cardiovascular Nursing.

[8] Mueller, X.M., Tinguely, F., Tevaearai, H.T., Revelly, J.P., Chiolero, R. and von Segesser, L.K. (2000) Pain Location, Distribution, and Intensity after Cardiac Surgery. Chest, 118, 391-396. http://dx.doi.org/10.1378/chest.118.2.391

[9] Gjeilo, K.H., Stenseth, R. and Klepstad, P. (2014) Risk Factors and Early Pharmacological Interventions to Prevent Chronic Postsurgical Pain Following Cardiac Surgery. American Journal of Cardiovascular Drugs, 14, 335-342.

[10] Eisenberg, E., Pultorak, Y., Pud, D. and Bar-El, Y. (2001) Prevalence and Characteristics of Post Coronary Artery Bypass Graft Surgery Pain (PCP). Pain, 92, 11-17. http://dx.doi.org/10.1016/S0304-3959(00)00466-8

[11] Choiniere, M., Watt-Watson, J., Victor, J.C., Baskett, R.J., Bussieres, J.S., Carrier, M., et al. (2014) Prevalence of and Risk Factors for Persistent Postoperative Nonanginal Pain after Cardiac Surgery: A 2-Year Prospective Multicentre Study. Canadian Medical Association Journal, 186, E213-E223.

[12] Gelinas, C. (2007) Management of Pain in Cardiac Surgery ICU Patients: Have We Improved over Time? Intensive and Critical Care Nursing, 23, 298-303. http://dx.doi.org/10.1016/j.iccn.2007.03.002

[13] Yorke, J., Wallis, M. and McLean, B. (2004) Patients’ Perceptions of Pain Management after Cardiac Surgery in an Australian Critical Care Unit. Heart \& Lung, 33, 33-41. http://dx.doi.org/10.1016/j.hrtlng.2003.09.002

[14] Mueller, X.M., Tinguely, F., Tevaearai, H.T., Revelly, J.P., Chiolero, R. and von Segesser, L.K. (2000) Pain Pattern and Left Internal Mammary Artery Grafting. The Annals of Thoracic Surgery, 70, 2045-2049. http://dx.doi.org/10.1016/S0003-4975(00)01947-0

[15] Bar-El, Y., Gilboa, B., Unger, N., Pud, D. and Eisenberg, E. (2005) Skeletonized Versus Pedicled Internal Mammary Artery: Impact of Surgical Technique on Post CABG Surgery Pain. European Journal Cardio-Thoracic Surgery, 27, 1065-1069. http://dx.doi.org/10.1016/j.ejcts.2005.02.016

[16] Cohen, A.J., Moore, P., Jones, C., Miner, T.J., Carter, W.R., Zurcher, R.P., et al. (1993) Effect of Internal Mammary Harvest on Postoperative Pain and Pulmonary Function. The Annals of Thoracic Surgery, 56, 1107-1109. http://dx.doi.org/10.1016/0003-4975(95)90025-X

[17] Aslan, F.E., Badir, A., Arli, S.K. and Cakmakci, H. (2009) Patients’ Experience of Pain after Cardiac Surgery. Contemporary Nurse, 34, 48-54. 
[18] Mello, L.C., Rosatti, S.F. and Hortense, P. (2014) Assessment of Pain during Rest and during Activities in the Postoperative Period of Cardiac Surgery. Revista Latino-Americana Enfermagem, 22, 136-143.

[19] Ferguson, J., Gilroy, D. and Puntillo, K. (1997) Dimensions of Pain and Analgesic Administration Associated with Coronary Artery Bypass Grafting in an Australian Intensive Care Unit. Journal of Advanced Nursing, 26, 1065-1072. http://dx.doi.org/10.1046/j.1365-2648.1997.00426.x

[20] Diby, M., Romand, J.A., Frick, S., Heidegger, C.P. and Walder, B. (2008) Reducing Pain in Patients Undergoing Cardiac Surgery after Implementation of a Quality Improvement Postoperative Pain Treatment Program. Journal of Critical Care, 23, 359-371. http://dx.doi.org/10.1016/j.jcrc.2007.11.005

[21] Voshall, B. (1980) The Effects of Preoperative Teaching on Postoperative Pain. Topics in Clinical Nursing, 2, 39-43.

[22] Meehan, D.A., McRae, M.E., Rourke, D.A., Eisenring, C. and Imperial, F.A. (1995) Analgesic Administration, Pain Intensity, and Patient Satisfaction in Cardiac Surgical Patients. American Journal of Critical Care, 4, 435-442.

[23] Raksamani, K., Wongkornrat, W., Siriboon, P. and Pantisawat, N. (2013) Pain Management after Cardiac Surgery: Are We Underestimating Post Sternotomy Pain? Journal of the Medical Association of Thailand, 96, 824-828.

[24] Silva, M.A., Pimenta, C.A. and Cruz Dde, A. (2013) Pain Assessment and Training: The Impact on Pain Control after Cardiac Surgery. Revista da Escola de Enfermagem da USP, 47, 84-92.

[25] Stolic, S. and Mitchell, M.L. (2010) Pain Management for Patients in Cardiac Surgical Intensive Care Units Has Not Improved Over Time. Australian Critical Care, 23, 157-159.

[26] van Gulik, L., Ahlers, S.J., Brkic, Z., Belitser, S.V., van Boven, W.J., van Dongen, E.P., et al. (2010) Improved Analgesia after the Realisation of a Pain Management Programme in ICU Patients after Cardiac Surgery. European Journal of Anaesthesiology, 27, 900-905. 